\title{
Dynamic load modelling for tank containers with the frame of circle pipes and structurally improved fittings
}

\author{
Oleksij Fomin ${ }^{1}$, Glib Vatulia ${ }^{2}$, and Alyona Lovska ${ }^{3, *}$ \\ ${ }^{1}$ State University of Infrastructure and Technologies, Department of Cars and Carriage Facilities, 9 Kyrylivska Str., Kyiv, 04071, \\ Ukraine \\ ${ }^{2}$ Ukrainian State University of Railway Transport, Department of Structural Mechanics and Hydraulics, 7 Feuerbach Sq., Kharkov, \\ 61050, Ukraine \\ ${ }^{3}$ Ukrainian State University of Railway Transport, Department of wagons, 7 Feuerbach Sq., Kharkov, 61050, Ukraine
}

\begin{abstract}
Higher efficiency of bulked cargo transportation along international transport corridors can be achieved with a resource-saving tank container described in the study. A characteristic feature of a tank container is the use of circle pipes as the carrying elements of the frame. In order to decrease impact loads between fittings of the tank container and fitting stops of the flat wagon at shunting impacts, the authors suggest filling fittings with viscous or viscoelastic materials of dumping or anticorrosive properties. The study also deals with modelling dynamic loading for the suggested tank container. The accelerations obtained were considered in strength calculations for a tank container as components of the dynamic loading. It was determined that the maximum equivalent loads did not exceed the admissible loads. The research will promote designing new-generation tank containers of improved technical, economical and ecological properties, and improve the working efficiency of combined transportation.
\end{abstract}

\section{Introduction}

Higher efficiency of bulked cargo transportation along international transport corridors has necessitated introduction of specialized transport means.

At present oil products are transported by tank wagons and tank containers. And it should be mentioned that recent years have witnessed a clear tendency to transfer part of bulked cargo transported from tank wagons to tank containers due to the mobility of the latter. And in recent years transportation of bulked cargo by tank containers is already estimated at the level of $18 \%$ annually out of the total bulked cargo turnover and this rate is going to increase.

Therefore, on-time delivery of oil products needs newgeneration tank containers. Some characteristic operational features should be taken into account as early as at the designing stage, particularly the structural loading for different means of transport.

One of the most difficult transportation in terms of power load on the carrying structure is transportation of tank containers by rail flat cars. It is taken that at shunting impacts of flat cars loaded with tank containers the rear stop of an automatic coupling is under a force of 3.5 MN [1-3]. It is considered that the tank container sustains an acceleration of $4.0 \mathrm{~g}$. However, with displacements between fitting stops and fittings the acceleration value can considerably increase. It can harm tank containers in operation and require an unscheduled repair. Therefore, while designing tank containers, it is of primary importance to guarantee their constructional adaption to certain operational conditions and compliance with the strength and durability requirements

\section{Analysis of recent researches}

At present, problems of improved carrying structures of vehicles have been considered by many engineers and designers in Ukraine and other countries. However, a further development of technical, economical and operational characteristics of rail transport means requires an extensive search for new engineering solutions [4-7].

Thus, study [8] deals with transfer of a heat flow through the carrying structure of a container. It describes simulation of a heat flow through the multilayer plastic support.

The results of optimization of the carrying structure of a tank container are given in [9]. The study confirms the need to design and implement tank containers as transport means. An improved tank container for transporting light oils was designed.

Tests on metal and composite containers under low temperatures are described in [10]. The study identifies some types of containers advisable for transporting certain types of cargo with consideration of low ambient temperatures.

It should be mentioned that the studies under examination do not consider problems of designing resource-saving tank containers.

The results of the research into the stressed state of an ISO tank container by the finite element method with

* Corresponding author: alyonaLovskaya.vagons@gmail.com 
ABAQUS software suite are given in [11]. The calculation was made under the static loading according to ISO 1496-3. The objective of the calculation was to define deflections of the frame angles and vertical deflections of the reservoir.

An improved structure of the support platform on the tank wagon for fluid cargo is presented in [12]. The strength calculation was made by the finite element method in Lira software.

However, the studies examined do not pose the problem of optimization of the carrying structures of tank containers to minimize the material capacity.

Considering the analysis of literature resources, we can conclude that, by far, the problems of designing resource-saving tank containers are not sufficiently highlighted.

The purpose of the article. The purpose of the article is to highlight characteristics of modelling dynamic loads on tank containers with frame of circular pipes and structurally improved fittings.

\section{Results and discussion}

In order to decrease the material capacity of a tank container the authors suggest optimization with the minimal material capacity criterion. A TK25 tank container manufactured by VAT Zarechinskiy Plant of Chemical Machine Building (ISO: 1CC) was taken as a basic structure (Fig. 1).

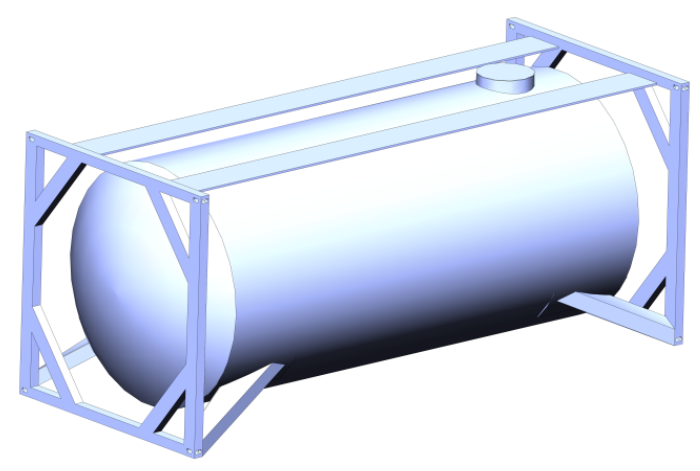

Fig. 1. A $1 C C$ tank container

The tank container consisted of a frame (of rectangular cross-section pipes) and a tank; it was fixed on the flat wagon with corner fittings.

A prospective approach in achieving the objective is implementation of profiles, as the carrying elements of the frame, which provide lower metal structural capacity and meet the strength requirements. An analysis of prospective profiles for car building industry, and the experience gained by other machine building industries confirmed the importance of applying circular section pipes as the carrying frame elements [13].

The authors suggest replacing rectangular pipes for circular pipes as the elements of the carrying structure of a tank container.

The vertical pipe diameter was chosen on the basis of geometrical features of the fitting $(D=152 \mathrm{~mm})$. The variation was made by changing the width of the wall $S$ of the pipe $(3-5.5 \mathrm{~mm})$. The inner diameter of the pipes changed within a range from 146.5 to $149 \mathrm{~mm}$.

The basic sizes, static characteristics and mass of circular section pipes calculated are given in Table 1.

Table 1. The sizes, static characteristics and mass of a one meter long pipe.

\begin{tabular}{|c|c|c|c|c|c|}
\hline \multicolumn{2}{|c|}{$\begin{array}{c}\text { Sizes of a pipe, } \\
\text { mm }\end{array}$} & \multirow{2}{*}{ 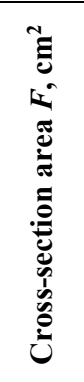 } & \multicolumn{2}{|c|}{$\begin{array}{c}\text { Static } \\
\text { characteristics } \\
\text { for axes } x \text { and } y\end{array}$} & \multirow{2}{*}{ 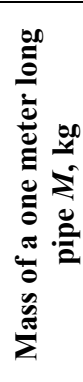 } \\
\hline 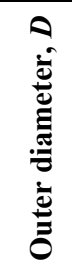 & 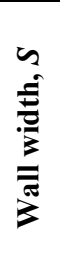 & & 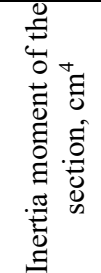 & 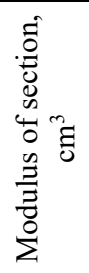 & \\
\hline \multirow[t]{8}{*}{152} & 3.0 & 14.04 & 389.87 & 51.30 & 11.02 \\
\hline & 3.2 & 14.96 & 414.21 & 54.50 & 11.74 \\
\hline & 3.5 & 16.33 & 450.35 & 59.26 & 12.82 \\
\hline & 3.8 & 17.69 & 486.04 & 63.95 & 13.89 \\
\hline & 4.0 & 18.60 & 509.59 & 67.05 & 14.60 \\
\hline & 4.5 & 20.85 & 567.61 & 74.69 & 16.37 \\
\hline & 5.0 & 23.09 & 624.43 & 82.16 & 18.13 \\
\hline & 5.5 & 25.31 & 680.06 & 89.48 & 19.87 \\
\hline
\end{tabular}

In order to optimize the tank container structure, spatial meta-models were built in SolidWorks software [14], the strength calculation was made with the finite element method [15-18]. The results of the research conducted are given in Table 2.

Table 2. The results of the strength calculation for the spatial models

\begin{tabular}{|c|c|c|c|c|}
\hline 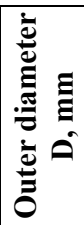 & 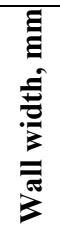 & 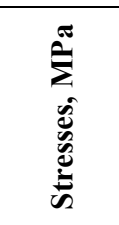 & 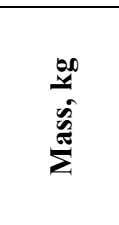 & 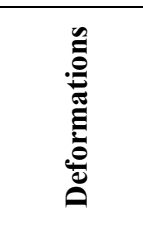 \\
\hline \multirow{9}{*}{152} & 3.0 & 318.32 & 1055.61 & $1.701 \cdot 10^{-3}$ \\
\hline & 3.2 & 316.466 & 1061.69 & $1.726 \cdot 10^{-3}$ \\
\hline & 3.5 & 315.482 & 1070.77 & $1.758 \cdot 10^{-3}$ \\
\hline & 3.8 & 314.525 & 1057.39 & $1.790 \cdot 10^{-3}$ \\
\hline & 4.0 & 313.639 & 1063.38 & $1.858 \cdot 10^{-3}$ \\
\hline & 4.5 & 311.555 & 1078.33 & $1.927 \cdot 10^{-3}$ \\
\hline & 5.0 & 311.664 & 1093.17 & $1.948 \cdot 10^{-3}$ \\
\hline & 5.5 & 310.8 & 1093.17 & $1.983 \cdot 10^{-3}$ \\
\hline & $5.5^{1}$ & 316.374 & 1075.17 & $1.868 \cdot 10^{-3}$ \\
\hline
\end{tabular}

To obtain the optimal frame structure (optimal structural geometric parameters of pipe sections to be used), the optimization research was made in the 
following order: it was determined that optimization be made by the minimal material capacity criterion $(m)$ with meeting the strength requirements (without exceeding the admissible stress values $\sigma$ ); on the basis of structural features, the limits at which variable values could change, i.e. the outer diameter of the pipe $(D)$ and the wall width $(S)$ were determined; it was determined that mathematical models of parametric variations $(m, \sigma, l)$ were described with two-factor generalized mathematical models which were defined through nine experiments based on the corresponding spatial computer models; and the mathematical models were determined, on the basis of which an additional schedule was built and optimal geometrical parameters of pipes were defined.

At the first stage, the decision was taken to use a circular pipe along the whole height of the vertical post of the tank container. The results of the strength calculation demonstrated that stresses in the contact area between the support and the vertical post did not exceed the admissible values for the steel grade of the metal structure of the tank container. Therefore, while building a spatial computer model of the tank container it was considered that the vertical post of circular section was located on the special superstructure (Fig. 2) in the form of a truncated pyramid. In order to decrease the impact loads between the fittings of the container and the fitting stops of the flat wagon under shunting impacts, when the impact loads exceeded the friction force between the horizontal planes of the fittings and fitting stops, the authors filled the fitting stops with elastic (Fig. 3, a) or viscoelastic (Fig. 3, b) materials of dumping or anti-corrosion properties.

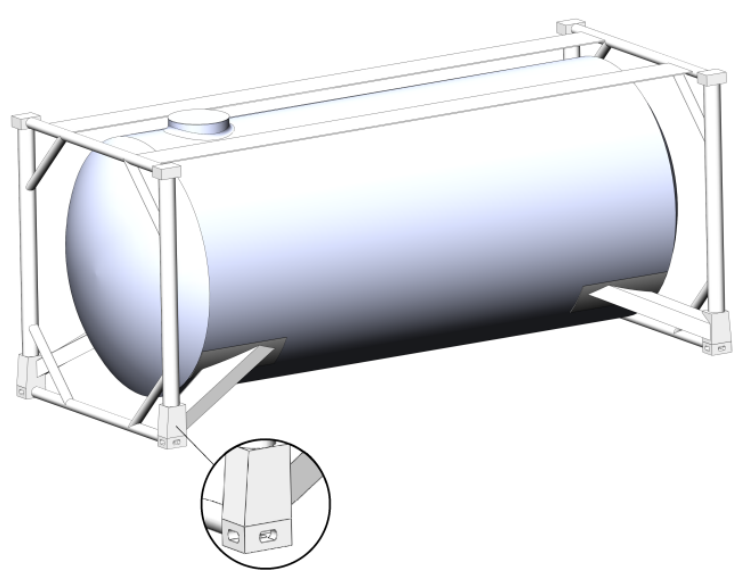

Fig. 2. The spatial model of an improved tank container.

Using the factor values obtained $(m, \sigma, l)$, the authors approximated them in the form of second-order polynomials:

$Y=f\left(x_{t_{1}}, x_{t_{2}}, x_{t_{3}}, x_{t_{a}}\right)=a_{0}+a_{1} x_{t_{1}}+a_{2} x_{t_{2}}+$ $a_{3} x_{t_{3}}+a_{4} x_{t_{a}}+a_{11} x_{t_{1}}^{2}+a_{11} x_{t_{1}}^{2}+a_{22} x_{t_{2}}^{2}+a_{33} x_{t_{3}}^{2}+$ $a_{44} x_{t_{a}}^{2}+a_{12} x_{t_{1}} x_{t_{2}}+a_{13} x_{t_{1}} x_{t_{3}}+a_{14} x_{t_{1}} x_{t_{a}}+$ $a_{23} x_{t_{2}} x_{t_{3}}+a_{24} x_{t_{2}} x_{t_{a}}+a_{34} x_{t_{3}} x_{t_{a}}$,

where $Y$ - the controlled value, $x_{t_{a}}$ - the control parameters, $a_{i}$ - the coefficients of a generalized mathematical model, the numeric values of which were defined through solving an equation system with the data obtained.
Generalized mathematical models and an additional schedule for the optimal pipe parameters of the tank container's frame were developed in a software suite.

The generalized mathematical models obtained have the following form:

$m=-70130+924.3 D+542.416 S-3 D^{2}+$ $2.048 S^{2}-3.6 D S$,

$s=22383.3-286.18 D-181.77 S+0.928858 D^{2}+$ $1.1853 S^{2}+1.1146 D S$,

$l=-0.4537+0.00591 D+0.0038 S-1.916 D^{2}-$

$0.000023 S^{2}-0.00002 D S$,

where $D$ - the outer diameter of the pipe, mm, $S$ - the pipe wall width, mm, $m$ - the structure mass, $\mathrm{kg}, l-$ the deformations in the structure, $\sigma$ - the stresses in the structure, $\mathrm{MPa}$.

(a)

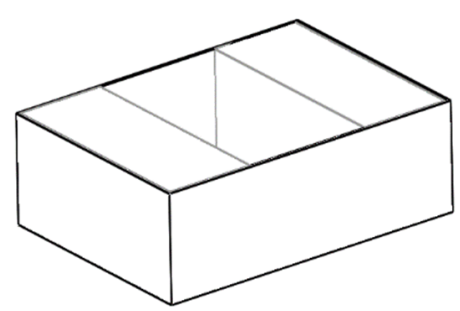

(b)

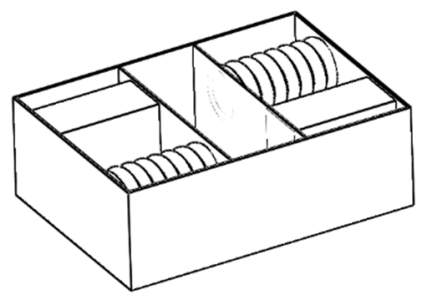

Fig. 3. The fittings of the tank container: (a) with viscous linkage, (b) with viscoelastic linkage.

The mathematic model verification $(2-4)$ was made by the mean square error value $[19,20]$ :

$$
\sigma=\sqrt{\frac{\sum_{j=1}^{m-k}\left(Y_{j}-Y_{j p}\right)^{2}}{m-k}},
$$

where $k$ - the number of coefficients $a_{i}$ of the generalized mathematical model; $m$ - the number of mathematic modes.

The calculations conducted confirmed the efficiency of the generalized mathematical models obtained [21-23]. And the mean square error value did not exceed $3 \%$.

In order to decrease the impact loads between fittings of the container and fitting stops of the flat wagon under shunting impacts, when the dynamic load $P_{d}$ exceeds the friction force $F_{F R}$ between horizontal planes of fittings and fitting stops, the authors suggest installing viscous or viscoelastic elements in the fittings of the container. 
In order to define the dynamic loading of the container in shunting impacts considering the improvements, a mathematical model (6) was built; the model took into account displacements of the container placed on the flat wagon.

$$
\left\{\begin{array}{l}
M_{F C}^{g w} \cdot \ddot{q}_{1}=P_{l}-\sum_{i=1}^{n}\left(F_{F R} \cdot \operatorname{sign}\left(\dot{q}_{1}-\dot{q}_{2}\right)+\beta_{v}\left(\dot{q}_{1}-\dot{q}_{2}\right)\right), \\
M_{C} \cdot \ddot{q}_{2}=\sum_{i=1}^{n}\left(F_{F R} \cdot \operatorname{sign}\left(\dot{q}_{1}-\dot{q}_{2}\right)+\beta_{v}\left(\dot{q}_{1}-\dot{q}_{2}\right)+\right. \\
\left.+M_{M} \cdot l \cdot q_{3}\right), \\
I_{m} \cdot \ddot{q}_{3}=M_{M} \cdot l \cdot \ddot{q}_{2}-g \cdot M_{M} \cdot l \cdot q_{3},
\end{array}\right.
$$

where $M_{F C}^{g w}$ - the gross weight of a flat wagon; $P_{l}$ - the value of longitudinal force on the automatic coupling; $F_{F R}$ - the friction force between fitting stops and fittings; $M_{C}$ - the tank container mass; $\beta_{v}$ - the viscous resistance coefficient in the container's fittings; $M_{M}$ - the mass of the pendulum imitating displacements of bulked cargo in the tank container; $l$ - the length of the pendulum suspension; $I_{m}$ - the inertia moment of the pendulum; $q_{1}, q_{2}, q_{3}$ - the coordinates indicating displacements of flat wagon, tank container and bulked cargo, respectively, relative to the longitudinal axis.

At the given viscous resistance in the container's fittings, the acceleration was approximately $40 \mathrm{~m} / \mathrm{sec}^{2}$ $(\approx 4 \mathrm{~g})$ and did not exceed the normalized value [24].

Besides, the total viscous resistance to displacements of one tank container should be within a range from 9 to $54 \mathrm{kN} \cdot \mathrm{sec} / \mathrm{m}$.

At viscoelastic linkage between fittings and fitting stops, the mathematical model has the form:

$$
\left\{\begin{array}{l}
M_{F C}^{g w} \cdot \ddot{q}_{1}=P_{l}-\sum_{i=1}^{n}\left(F_{F R} \cdot \operatorname{sign}\left(\dot{q}_{1}-\dot{q}_{2}\right)+C_{v}\left(q_{1}-q_{2}\right)+\right. \\
+\beta_{v}\left(\dot{q}_{1}-\dot{q}_{2}\right), \\
M_{C} \cdot \ddot{q}_{2}=\sum_{i=1}^{n}\left(F_{F R} \cdot \operatorname{sign}\left(\dot{q}_{1}-\dot{q}_{2}\right)+C_{v}\left(q_{1}-q_{2}\right)+\right. \\
\left.+\beta_{v}\left(\dot{q}_{1}-\dot{q}_{2}\right)+M_{M} \cdot l \cdot q_{3}\right), \\
I_{m} \cdot \ddot{q}_{3}=M_{M} \cdot l \cdot \ddot{q}_{2}-g \cdot M_{M} \cdot l \cdot q_{3},
\end{array}\right.
$$

where $C_{v}$ - the rigidity of the elastic elements in the tank container's fittings.

The rigidity of an elastic element was taken $480 \mathrm{kN} / \mathrm{m}$, and the viscous resistance coefficient $-30 \mathrm{kN} \cdot \mathrm{sec} / \mathrm{m}$. The maximum acceleration was about $40 \mathrm{~m} / \mathrm{sec}^{2}(\approx 4 \mathrm{~g})$ and did not exceed the normalized value.

The acceleration values obtained were considered in strength calculations for the tank container.

The strength calculation was made with the finite element method in SolidWorks software suite [25-27]. When designing the finite element model of the tank container, isoparametrical tetrahedrons were used; the optimal number of them was determined with the graphoanalytical method.

The basic characteristics of the finite-element model for the optimized tank container are given in Table 3.
Table 3. The basic characteristics of the finite-element method of the optimized tank container

\begin{tabular}{|l|c|}
\hline \multicolumn{1}{|c|}{ Parameter } & Value \\
\hline The number of Jacobian points & 4 \\
\hline The number of units & 376555 \\
\hline The number of elements & 1162350 \\
\hline The maximum size of an element, mm & 20 \\
\hline The minimum size of an element, mm & 4 \\
\hline The minimum number of elements in a circle & 10 \\
\hline Ratio of an element size expansion & 1.7 \\
\hline Maximum side ratio & 177.52 \\
\hline Percent of elements with a side ratio less than 3 & 36.7 \\
\hline Percent of elements with a side ratio more than 10 & 0.939 \\
\hline
\end{tabular}

While designing the strength model for the tank container, it was considered that the structure was effected by vertical static loads $P_{v}{ }^{s t}$, pressure of bulked cargo $P_{p}$, longitudinal pressure on the bottom $P_{l}$, horizontal pressure on the fitting stop $P_{h p}$ conditioned by the force $P_{n}$, and vertical load on the fitting $P_{v}$ conditioned by $P_{v}{ }^{s t}$ (Fig. 4).

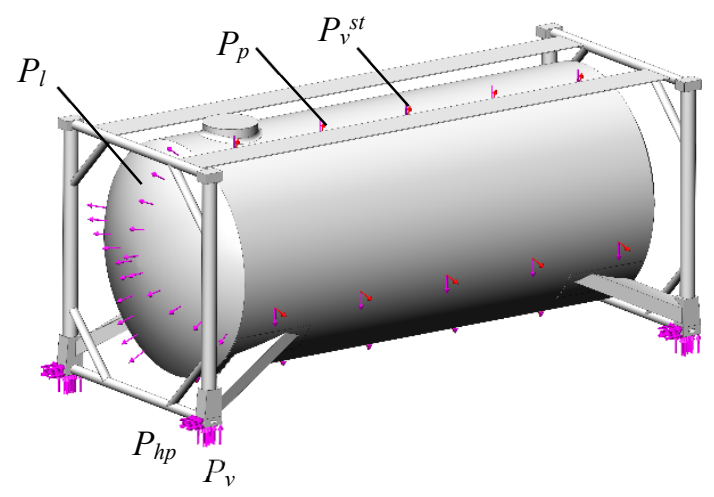

Fig. 4. The design diagram of the tank container.

The tank container was fixed in the areas where the flat wagon rested on fitting stops. The 09G2C steel was used as a construction material.

The maximum equivalent stresses were 294.1 MPa (Fig. 5, 6). The maximum displacements were concentrated in the area of the access door and accounted for $7.24 \mathrm{~mm}$ (Fig. 7, 8), the maximum deformations were $2.79 \cdot 10^{-3}$ (Fig. 9, 10).

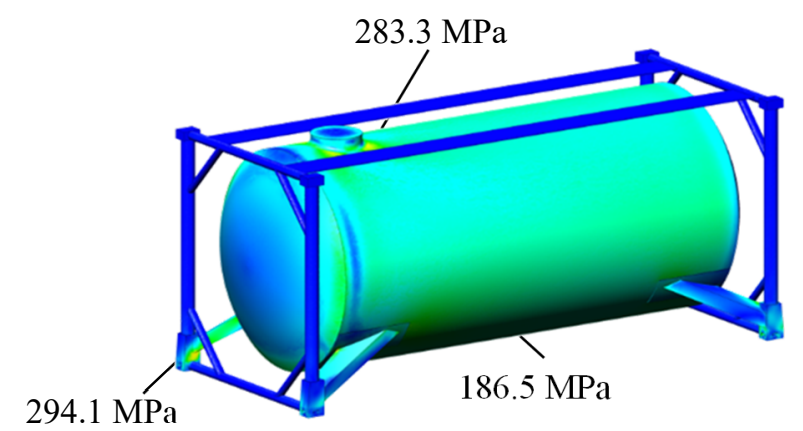

Fig. 5. Stressed state of the tank container.

Thus, the research conducted confirmed the efficiency of decisions taken during designing the tank container. 


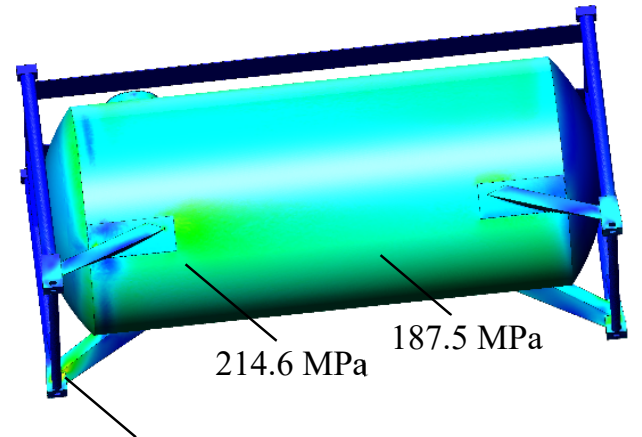

$283.3 \mathrm{MPa}$

Fig. 6. Stressed state of the tank container (bottom view).

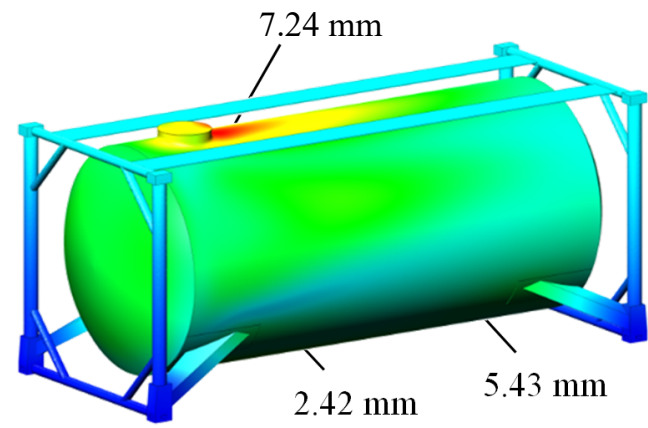

Fig. 7. Displacements in the tank container.

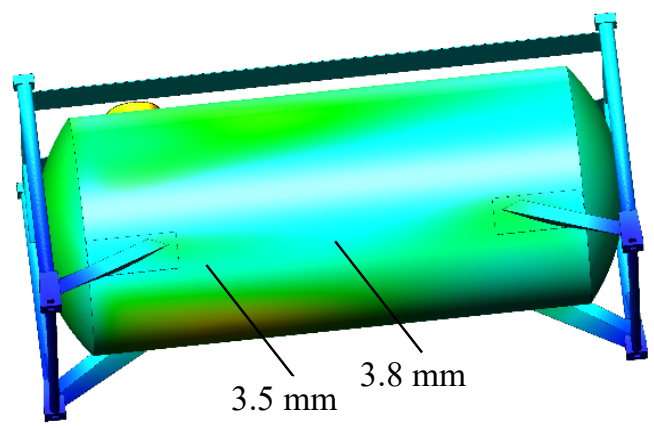

Fig. 8. Displacements in the tank container (bottom view).

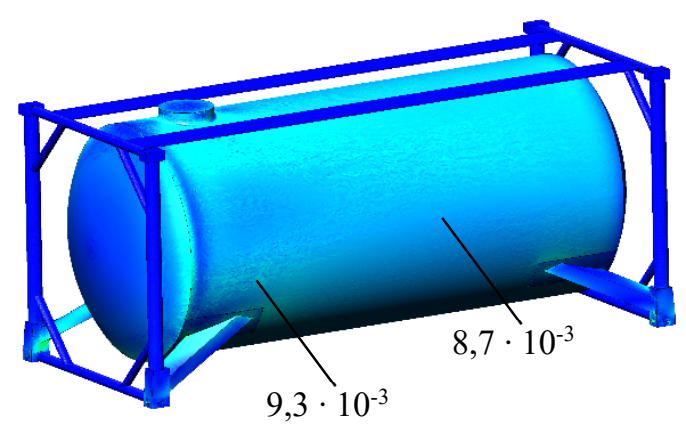

Fig. 9. The deformations in the tank container.

\section{Conclusions}

The following conclusions can be made on the basis of the research:

1. The carrying structure of the tank container was optimized with circular pipes for the frame. The vertical post of the frame was located on the special superstructure in the form of a truncated pyramid. It was determined that the mass of the optimized frame was less than that of a typical one by about $20 \%$;

2. In order to decrease the impact loads between the fittings of the container and fitting stops of the flat wagon under shunting impacts, when the impact loads exceeded the friction force between the horizontal planes of fittings and fitting stops, the authors suggested filling fitting stops with elastic or viscoelastic materials of dumping or anticorrosion properties.

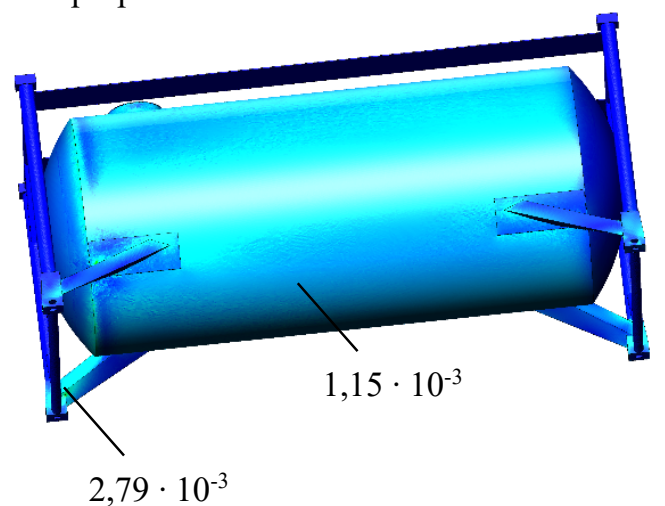

Fig. 10. The deformations in the tank container (bottom view).

The optimized structure of the tank container was calculated for strength. The maximum equivalent stresses were 294.1 MPa. The maximum displacements were concentrated in the area of an access door and accounted for $7.24 \mathrm{~mm}$, the maximum deformations were $2.79 \cdot 10^{-3}$. The research conducted will promote designing newgeneration tank containers, thus improving the efficiency of rail transportation along international transport corridors.

The research was made within the taxpayer-funded research "Innovative approaches in designing resource-saving car structures with consideration of refined dynamic loading and functional-adaptive flash-concepts".

\section{References}

1. Freight wagons. General requirements for designing new and improved wagons (non-self-propelled) for a 1520mm gauge. DSTU 7598 (Kyiv, 2015), p. 162

2. Freight wagons. Requirements for strength and dynamic qualities. GOST 33211 (Standartinform, Moscow, 2016), p. 54

3. Railway applications - Structural requirements of railway vehicle bodies. Part 2: Freight wagons. EN 12663-2 (BSI, Bulgaria, 2010), p. 54

4. O. Fomin, J. Gerlici, A. Lovskaya, K. Kravchenko, P. Prokopenko, A. Fomina, V. Hauser, Research of the strength of the bearing structure of the flat wagon body from round pipes during transportation on the railway ferry. MATEC Web of Conferences 235 (2018)

5. A.V. Kondratiev,

V.E. Gaidachuk, M.E. Kharchenko, Relationships between the ultimate strengths of polymer composites in static 
bending, compression, and tension. Mechanics of Composite Materials 52(2), 259-266 (2019)

6. P. Kucera, V. Pistek, Testing of the mechatronic robotic system of the differential lock control on a truck. International Journal of Advanced Robotic Systems 14(5) (2017)

7. V. Pistek, L. Klimes, T. Mauder, P. Kucera, Optimal design of structure in rheological models: An automotive application to dampers with high viscosity silicone fluids. Journal of Vibroengineering 19(6), 4459-4470 (2017)

8. W. Czyżycki, Modeling of heat flow through multilayer internal supports of cryogenic vessels. Technical transportations 2, 27-34 (2015)

9. S. Myamlin, Y. Kebal, S. Kondratyuk, Perspective constructions of tank-containers for transportation of light oil products, ammonia and hydrocarbon gases. Rail transport Ukraine 2, 44-46 (2012)

10. J. Föhr, K. Karttunen, J. Enström, T. Johannesson, T. Ranta, Metal and Composite Intermodal Containers in Comparative Cold Tests with Wood Chips. Journal of Sustainable Bioenergy Systems 05(01), 32-39 (2015)

11. B. Rudraprasad, H. Abhishek, in Proceedings of 58th Congress of ISTAM, India, 2013

12. G. Vatulia, A. Falendysh, Y. Orel, M. Pavliuchenkov, Structural Improvements in a Tank Wagon with Modern Software Packages. Procedia Engineering 187, 301-307 (2017)

13. Steel shapes tubes for metal structures. Technical requirements. GOST R54157-2010 (IPK Standards Publishing, Moscow, 2012), p. 92

14. Matt Weber, Gaurav Verma, SolidWorks Simulation 2015 Black Book II Edition (CreateSpace Independent Publishing Platform, 2015)

15. P. Seshu, Finite Element Analysis (PHI Learning Private Limited, 2012)

16. Zhu Bofang, The finite element method: Fundamentals and Applications in Civil, Hydraulic, Mechanical and Aeronautical engineering (China Institute of water resources and gidropower research, 2018)

17. A. Reyes, Beginners guide to SolidWorks 2018 (SDC Publications, 2017)

18. P. Kurowski, Engineering Analysis with SOLIDWORKS Simulation 2010 (Schroff Development Corporation, 2010)

19. V.M. Rudenko, Mathematical statistics (Center of educational literature, Kyiv, 2012)

20. A.I. Kobzar, Applied Mathematical Statistics. For engineers and scientists (Fismatlit, Moscow, 2012)

21. A. Borovkov, Mathematical Statistics. Textbooks for universities. Special literature (Lan, Moscow, 2010)

22. G.I. Ivchenko, Yu.I. Medvedev, Mathematical statistics (Librocom, Moscow, 2014)
23. V.V. Garbaruk, Yu.Yu. Pupysheva, Mathematical statistics (Petersburg State University of Railway Engineering, Petersburg, 2012), p. 56

24. Containers for the transport of dangerous goods. Requirements for operational safety. GOST 31232 (Belarusian State Institute for Standardization and Certification, Minsk, 2005), p. 6

25. P. Kurowski, Engineering Analysis with SOLIDWORKS Simulation 2019 (Schroff Development Corporation, 2019)

26. A.A. Alyamovsky, Engineering calculations in SolidWorks (DMK Pres, 2010)

27. A.A. Alyamovsky, Engineering calculations in SolidWorks Simulation, $2^{\text {nd }}$ edn (DMK Pres, 2015) 